REFERENCES:

[1] doi:10.1017/s0021932017000244.

[2] doi:10.1016/j.maturitas.2019.03.008.

\begin{tabular}{|c|c|c|c|}
\hline & \multicolumn{2}{|c|}{ Pregnancies } & \multirow[t]{2}{*}{$\mathbf{p}$} \\
\hline & Before TA $(n=200)$ & After TA $(n=33)$ & \\
\hline Number of Patients & 71 & 19 & $N P$ \\
\hline $\begin{array}{l}\text { Age at TA diagnosis, years mean } \\
\text { (SD) }\end{array}$ & $38.2(13.1)$ & $24.0(6.6)$ & \\
\hline Age at first pregnancy & $21.7(5.0)$ & $27.6(5.0)$ & \\
\hline $\begin{array}{l}\text { Comorbidities/CV Risk factors } \\
\mathrm{n}(\%)\end{array}$ & \multicolumn{2}{|c|}{ n (\%) } & $\mathbf{p}$ \\
\hline - Smoking & $22(31)$ & $3(15.8)$ & $>0.05$ \\
\hline - Dyslipidemia & $14(19.7)$ & $1(5.3)$ & \\
\hline - Hypertension & $29(40.8)$ & $9(47.4)$ & \\
\hline - Diabetes mellitus & $8(11.3)$ & $0(0)$ & \\
\hline Maternal Complications & \multicolumn{2}{|c|}{ n (\%) } & \\
\hline $\begin{array}{l}\text { Numbers of pregnancies with } \\
\text { any maternal complications }\end{array}$ & $22(11.0)$ & $8(24.2)$ & 0.048 \\
\hline - Gestational hypertension & $6(3.0)$ & $4(12,1)$ & $N P$ \\
\hline - PROM & $6(3.0)$ & $1(3.0)$ & \\
\hline - GDM & $0(0)$ & $0(0)$ & \\
\hline $\begin{array}{l}\text { - Bleeding (Antepartum/ } \\
\text { postpatum) }\end{array}$ & $6(3.0)$ & $2(6.1)$ & \\
\hline - Preeclampsia & $0(0.0)$ & $0(0.0)$ & \\
\hline - İnfection & $5(2.5)$ & $1(3.0)$ & \\
\hline - Placenta previa & $0(0)$ & $1(3.0)$ & \\
\hline Fetal Complications & \multicolumn{2}{|c|}{ n (\%) } & p \\
\hline $\begin{array}{l}\text { Numbers of pregnancies with } \\
\text { any fetal complications }\end{array}$ & $43(21.5)$ & $11(33.3)$ & 0.180 \\
\hline - LBW & $16(8.0)$ & $6(18.2)$ & NP \\
\hline - IUGR & $20(1.0)$ & $5(15.2)$ & \\
\hline - Preterm birth & $13(6.5)$ & $7(21.2)$ & \\
\hline - CNS complications & $2(1.0)$ & $1(3.0)$ & \\
\hline - Cardiovascular complications & $3(1.5)$ & $0(0)$ & \\
\hline - RDS_BPD & $4(2.0)$ & $0(0)$ & \\
\hline - NICU admission & $12(6.0)$ & $1(3.0)$ & \\
\hline - Other & $5(2.5)$ & $0(0)$ & \\
\hline - Neonatal death & $5(2.5)$ & $0(0)$ & \\
\hline - Retinopathy of prematurity & $1(0.5)$ & $0(0)$ & \\
\hline - Stillbirth & 7 (3.5) & $0(0)$ & \\
\hline Delivery & \multicolumn{2}{|c|}{$n(\%)$} & $\mathbf{P}$ \\
\hline Vaginal delivery & $128(64)$ & $6(18.2)$ & $<0.001$ \\
\hline Cesarean & $24(12)$ & $13(39.4)$ & $<0.001$ \\
\hline Spontaneous abortus & $21(10.5)$ & $7(21.2)$ & 0.088 \\
\hline Termination of pregnancy & $18(9.0)$ & $7(21.2)$ & 0.061 \\
\hline
\end{tabular}

Abbreviations: BPD: Bronchopulmonary dysplasia, CNS: Central nervous system, GDM: Gestational diabetes mellitus, IUGR: Intrauterin growth restriction, LBW: Low birth weight, NICU: Neonatal Intensive Care Unit, NP: Not performed PROM: Premature rupture of membranes, RDS: Respiratory distress syndrome

Disclosure of Interests: None declared DOI: 10.1136/annrheumdis-2021-eular.3231

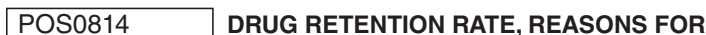 DISCONTINUATION AND OUTCOME OF INFLIXIMAB USE IN BEHÇET SYNDROME}

S. N. Esatoglu ${ }^{1,2}$, B. Tukek ${ }^{3}$, S. S. Taflan ${ }^{3}$, Y. Ozyazgan ${ }^{4}$, D. Ucar ${ }^{4}$ V. Hamuryudan ${ }^{1,2}$, Y. Ozguler ${ }^{1,2}$, E. Seyahi ${ }^{1,2}$, M. Melikoglu ${ }^{1,2}$, U. Uygunoglu ${ }^{5}$, A. Siva ${ }^{5}$, Z. Kutlubay ${ }^{6}$, I. Fresko ${ }^{1,2}$, S. Yurdakul ${ }^{1}$, H. Yazici ${ }^{1,2}$, G. Hatemi ${ }^{1,2}$ ${ }^{1}$ Istanbul University-Cerrahpasa, Cerrahpasa Medical Faculty, Department of Internal Medicine, Division of Rheumatology, Istanbul, Turkey; ${ }^{2}$ Istanbul University-Cerrahpasa, Cerrahpasa Medical Faculty, Behcet Disease Center, Istanbul, Turkey; ${ }^{3}$ Istanbul University-Cerrahpasa, Cerrahpasa Medical Faculty, Department of Internal Medicine, Istanbul, Turkey;

${ }^{4}$ Istanbul University-Cerrahpasa, Cerrahpasa Medical Faculty, Department of Ophthalmology, Istanbul, Turkey; ${ }^{5}$ Istanbul University-Cerrahpasa,

Cerrahpasa Medical Faculty, Department of Neurology, Istanbul, Turkey;

${ }^{6}$ Istanbul University-Cerrahpasa, Cerrahpasa Medical Faculty, Department of Dermatology, Istanbul, Turkey

Background: Infliximab (IFX) plays a key role in the management of severe and refractory manifestations of Behçet syndrome (BS). However we had previously shown that its sustained use may be limited due to adverse events and lack of patient compliance (1)

Objectives: To assess the retention rate of IFX, adverse events, causes of discontinuation and outcome after cessation of IFX in a larger group of BS patients who were followed in a tertiary center.

Methods: The charts of BS patients who were prescribed IFX between 2004 and 2020 were reviewed to determine demographic features, reasons for IFX use, previous and concomitant drugs, IFX duration, reasons for cessation of IFX and time to flare following cessation of IFX. Follow-up was censored on March 2020.

Results: A total of 252 patients (195 men, mean age $40 \pm 10$ years) received IFX for uveitis $(n=122)$, vascular involvement $(n=82)$, parenchymal neurologic involvement $(n=32)$, gastrointestinal involvement $(n=11)$, arthritis $(n=10)$, mucocutaneous involvement $(n=4)$, and secondary amyloidosis $(n=1)$. Ten patients had more than 1 involvement requiring IFX.

During a median follow-up of 52 (IQR: 30-88) months, 122 (48\%) patients were still receiving IFX for a median period of 33 (IQR: $15-56)$ months while $130(52 \%)$ patients had discontinued IFX after a median follow-up of 17 (IQR: 7-31) months. Reasons for discontinuation were remission in $25(19 \%)$ patients, adverse events in $39(30 \%)$, lack of efficacy in $23(18 \%)$ (4 primary and 19 secondary), lack of patient compliance in $36(28 \%)$, pregnancy in 4 , and preparation for surgery in 3 patients.

Adverse events $(n=39)$ that required the cessation of IFX were infusion reaction $(n=17)$, infection $(n=7)$, hepatotoxicity $(n=4)$, malignancy $(n=4)$, palmoplantar psoriasis $(n=3)$, lichen planus $(n=1)$, drug induced lupus $(n=1)$, splenic infarction $(n=1)$, and a decrease in left ventricular ejection fraction $(n=1)$.

Among the 25 patients who discontinued IFX due to remission, 5 (20\%) had a relapse after $4,21,26,29,38$ and 46 months. The remaining patients did not experience a relapse during a median follow-up of 35 (IQR: 24-68) months.

\begin{tabular}{|c|c|c|c|c|c|}
\hline Reasons for infliximab treatment & $\begin{array}{c}\text { No of } \\
\text { patients }\end{array}$ & $\begin{array}{l}\text { No }(\%) \text { of patients who were } \\
\text { still receiving infliximab }\end{array}$ & $\begin{array}{l}\text { Number }(\%) \text { of patients who } \\
\text { discontinued infliximab }\end{array}$ & Reasons for discontinuation & $\begin{array}{l}\text { Duration of infliximab use } \\
\text { (median (IQR) months) }\end{array}$ \\
\hline Eye involvement & 122 & $59(48)$ & $63(52)$ & $\begin{array}{c}\text { Remission }(n=17) \\
\text { Inefficacy }(n=10) \\
\text { Lack of patient compliance }(n=19) \\
\text { Adverse event }(n=12) \\
\text { Others }(n)=5)\end{array}$ & $28(12.5-52)$ \\
\hline Vascular involvement & 82 & $40(49)$ & $42(51)$ & $\begin{array}{c}\text { Remission }(n=10) \\
\text { Inefficacy }(n=7) \\
\text { Lack of patient compliance }(n=12) \\
\text { Adverse event }(n=12) \\
\text { Others }(n=4)\end{array}$ & $18.5(9-33.5)$ \\
\hline Parenchymal neurologic involvement & 32 & $21(66)$ & $11(34)$ & $\begin{array}{c}\text { Adverse event }(n=8) \\
\text { Inefficacy }(n=2) \\
\text { Lack of patient compliance }(n=1)\end{array}$ & $25(14.5-50)$ \\
\hline Gastrointestinal involvement & 11 & $4(36)$ & $7(64)$ & $\begin{array}{c}\text { Remission }(n=1) \\
\text { Inefficacy }(n=1) \\
\text { Adverse event }(n=2) \\
\text { Lack of patient compliance }(n=4)\end{array}$ & $7(2-17)$ \\
\hline Joint involvement & 10 & $2(20)$ & $8(80)$ & $\begin{array}{c}\text { Inefficacy }(n=1) \\
\text { Adverse event }(n=5) \\
\text { Lack of patient compliance }(n=2)\end{array}$ & $20(4-35)$ \\
\hline $\begin{array}{l}\text { Mucocutaneous involvement } \\
\text { AA amyloidosis }\end{array}$ & $\begin{array}{l}4 \\
1\end{array}$ & $\begin{array}{l}3 \\
0\end{array}$ & $\begin{array}{l}1 \\
1\end{array}$ & $\begin{array}{l}\text { Inefficacy }(n=1) \\
\text { Inefficacy }(n=1)\end{array}$ & $\begin{array}{c}6,10,12,104 \text { months } \\
6 \text { years }\end{array}$ \\
\hline
\end{tabular}


At the end of the follow-up, 2 patients had died due to lung adenocarcinoma during IFX treatment and 3 patients had died 1 year, 3 and 8 years after IFX discontinuation. The causes of death were with right heart failure due to pulmonary hypertension in 1 , and severe nervous system involvement in 2 of the patients.

Conclusion: Despite its successful use for the management of potentially organ and life-threatening manifestations in more than half of our patients with BS, long term maintenance was not possible in $42 \%$, mainly due to adverse events, lack of patient compliance and inefficacy.

REFERENCE:

[1] Esatoglu SN, Tukek B, Taflan SS, et al. SAT0258 Drug Retention Rate and Prognosis After Discontinuation of Infliximab in Patients with Behçet Syndrome. Annals of the Rheumatic Diseases 2020;79: 1071-1072.

Disclosure of Interests: None declared

DOI: 10.1136/annrheumdis-2021-eular.3262

\section{POS0815 \\ CLINICAL CHARACTERISTICS, IMAGING PHENOTYPE, AND LONG-TERM OUTCOMES OF TAKAYASU ARTERITIS PATIENTS WITH HYPERTENSION}

Y. Sun ${ }^{1}$, L. Ma ${ }^{1}$, H. Chen ${ }^{1,2}$, C. Rongyi ${ }^{2}$, L. Jiang ${ }^{2} .{ }^{1}$ Zhonngshan Hospital, Fudan University, Rheumatology, Shanghai, China; ${ }^{2}$ Zhonngshan Hospital, Fudan University, Rheumatology, Shanghai, China

Background: Hypertension occurred in $30-80 \%$ of TAK patients around the world. The occurrence of hypertension might severely worsen TAK prognosis. Nevertheless, data describing the specific imaging features in hypertensive TAK patients and the associations between hypertensive severity, blood pressure control status and long-term outcome were still lacking.

Objectives: To investigate the characteristics and associations of hypertensive characteristics with adverse events-free survival in Takayasu arteritis (TAK) patients with hypertension.

Methods: This research was based on a prospectively on-going observational cohort-East China Takayasu Arteritis (ECTA) cohort. In all, 618 TAK patients, who registered in the ECTA cohort up to December 2019, were enrolled. The main outcome was the adverse-events-free survival among hypertensive TAK patients during the follow-up ended on August 2020.

Results: Totally, 204 (33.0\%) patients suffered from hypertension, with 48 $(23.5 \%), 62(30.4 \%)$, and 94 (46.1\%) mild, moderate, and severe hypertension, respectively. Cluster analysis indicated three imaging phenotypes for hypertensive TAK patients: Cluster 1: involvement of the abdominal aorta and/ or renal artery $(n=56,27.5 \%)$; Cluster 2 : involvement of the ascending aorta, thoracic aorta, and the aortic arch and its branches $(n=38,18.6 \%)$; Cluster 3: combined involvement of Cluster 1 and Cluster $2(n=111,54.4 \%)$. By the end of the follow-up, the blood pressure control rate was $50.8 \%$, while the adverse-events-free survival was $67.9 \%$ in the entire hypertensive population. Multivariate Cox regression analysis indicated that well-controlled blood pressure $(\mathrm{HR}=2.13,95 \% \mathrm{Cl} 1.32-3.78, \mathrm{p}=0.047)$, co-existence of severe aortic valve regurgitation $(\mathrm{HR}=0.87,95 \% \mathrm{Cl} 0.64-0.95, p=0.043)$, Cluster $1(\mathrm{HR}=0.69,95 \% \mathrm{Cl} 0.48-0.92, \mathrm{p}=0.017)$ and Cluster $3(\mathrm{HR}=0.72,95 \% \mathrm{Cl}$ $0.43-0.94, p=0.048)$ imaging phenotype was associated with the adverseevents-free survival.

Conclusion: Patients with controlled hypertension showed better adverseevents-free survival, while those with the Cluster 1 imaging phenotype were more likely to suffer from worse adverse-events-free survival. Hypertension occurred in $30-80 \%$ of TAK patients around the world. The occurrence of hypertension might severely worsen TAK prognosis.

REFERENCES:

[1] Johnston SL, Lock RJ, Gompels MM. Takayasu arteritis: a review. J Clin Pathol 2002; 55:481-6.

[2] Watanabe Y, Miyata T, Tanemoto K. Current clinical features of new patients with Takayasu arteritis observed from a cross-country research in Japan: age and sex specificity. Circulation 2015; 132:1701-9.

[3] Yilmaz N, Can M, Oner FA, et al. Impaired quality of life, disability and mental health in Takayasu's arteritis. Rheumatol. (Oxford) 2013; 52:1898-904.

[4] Laurent A, Julien H, Nicolas L, et al. Takayasu arteritis in France: a single-center retrospective study of 82 cases comparing white, North African, and black patients. Medicine 2010; 89:1-17.

[5] Mwipatayi BP, Jeffery PC, Beningfield SJ, et al. Takayasu arteritis: clinical features and management: report of 272 cases. ANZ J Surg 2005; 75:110-7.

Disclosure of Interests: None declared

DOI: 10.1136/annrheumdis-2021-eular.3494

\section{POS0816 PROGNOSTIC FACTORS FOR AGGRAVATED VASCULAR DAMAGE IN TAKAYASU ARTERITIS}

R. Chen ${ }^{1,1}$, L. Ma ${ }^{1}$, Y. Liu' ${ }^{1}$, L. Ma' ${ }^{1}$, L. Jiang ${ }^{1} .{ }^{1}$ Zhongshan Hospital Fudan University, Rheumatology, Shanghai, China

Background: Takayasu arteritis is a rare disease characterized by inflammation in the aorta and its branches. Some patients were discovered to suffer the aggravated vascular damage (AVD), monitored by imaging techniques, even with the effective anti-inflammation treatment. But the general characteristics and the related prognostic factors of AVD in TA were unclear yet.

Objectives: We aimed to describe the characteristics of the AVD and identify its prognostic factors in TA.

Methods: From the living East China Takayasu arteritis cohort, patients who underwent at least two magnetic resonance angiography (MRA) examinations at Zhongshan Hospital from April 2009 to April 2019 were enrolled as the derivation cohort to explore the prognostic factors of AVD in MRA. An independent group of patients from May 2019 to July 2020 comprising the validation cohort were used to validate the nomogram formed by these prognostic factors.

Results: Among 235 enrolled patients, 69 patients (29.3\%) suffered AVD with the median follow-up of 14 months. The limb arteries were the most vulnerable and the aggravated vascular stenosis were the most commonly seen in AVD. Patients with AVD were younger, had higher complement 4 levels at baseline, and lower disease remission rate at 6 months. Multivariate cox regression analysis revealed that younger age (HR: 0.25-0.42 95\% $\mathrm{Cl}: 0.09-0.91)$, higher CRP levels $(\mathrm{HR}=2.57,95 \% \mathrm{Cl}: 1.51-4.36)$ at baseline, and lower remission rate at 6 months $(\mathrm{HR}=0.36,95 \% \mathrm{Cl}: 0.21-$ 0.64 ) were significant predictors. In the validation cohort of 65 patients, 19 cases had AVD. The predictive nomogram based on these factors achieved C-indices of 0.745 and 0.641 in the derivation and validation cohort respectively.

Conclusion: Totally, $29.3 \%$ of patients suffered AVD, among which the aggravated vascular stenosis and limb arteries involvement were most commonly seen. Younger age, higher CRP at baseline, and lower disease remission rate at 6 months were prognostic factors for AVD.

\section{REFERENCES:}

[1] M. Bredemeier, C.M. Rocha, M.V. Barbosa, E.H. Pitrez. One-year clinical and radiological evolution of a patient with refractory Takayasu's arteritis under treatment with tocilizumab. Clin Exp Rheumatol 2012; 30 (Suppl. 70): S98-S100.

Disclosure of Interests: None declared

DOI: 10.1136/annrheumdis-2021-eular.3720

\section{\begin{tabular}{|l|l}
\hline POS0817 & A NOVEL MODEL TO ASSESS DISEASE ACTIVITY IN \\
\hline
\end{tabular} TAKAYASU ARTERITIS BASED ON 18F-FDG-PET/CT: A CHINESE COHORT STUDY}

L. $\mathrm{Ma}^{1}$, B. $\mathrm{Wu}^{2}$, X. $\mathrm{Jin}^{3}$, Y. Sun ${ }^{1}$, X. Kong ${ }^{1}$, Z. Ji ${ }^{1}$, R. Chen ${ }^{1}$, X. Cui ${ }^{1}$, H. Shi ${ }^{2}$, L. Jiang ${ }^{1}$. 'Zhongshan Hospital, Fudan University, Department of Rheumatology, Shanghai, China; '2hongshan Hospital, Fudan University, Department of Nuclear Medicine, Shanghai, China; ${ }^{3}$ Zhongshan Hospital, Fudan University, Department of Medical Statistics, Shanghai, China

Background: Takayasu arteritis (TA) is a condition characterized by major large-vessel vasculitis (LVV), and is most commonly found in young women (age $<40$ years) of East Asia countries. 18F-FDG-PET/CT has been widely used in the diagnosis and follow-up of cancers to gather functional information based on metabolic activity. In the present study, we evaluated the value of different parameters in 18F-FDG-PET/CT for assessing active TA disease, and we establish a simple, quantifiable, and effective disease activity evaluation model based on 18F-FDG-PET/CT. A comparison in the ability to identify active disease was performed between the established Kerr score and the new 18F-FDG-PET/CT was also performed.

Objectives: To investigate the utility of $18 \mathrm{~F}$-fluorodeoxyglucose positron emission tomography/computed tomography (18F-FDG-PET/CT) in assessing disease activity in TA.

Methods: Ninety-one patients with TA, were recruited from a Chinese cohort from October 2017 to January 2019. Clinical data, acute-phase reactants (APRs), and 18F-FDG-PET/CT findings were simultaneously recorded. The Physician Global Assessment was used as the gold standard to assess TA disease activity. The value of using 18F-FDG-PET/CT to identify active disease 